\title{
Bovinos submetidos a dietas deficientes em energia por longo período: desempenho animal e sua relação com os teores de $\mathrm{T}_{3}$ e IGF-1
}

\author{
Long term dietary energy deficiency in steers: performance animal and $T_{3}$ and IGF-1 \\ relationships
}

\author{
Alessandra Silva LIMA ${ }^{1}$; Maria Claudia Araripe SUCUPIRA ${ }^{1}$; Enrico Lippi ORTOLANI ${ }^{1}$ \\ ${ }^{1}$ Departamento de Clínica Médica da Faculdade de Medicina Veterinária e Zootecnia da Universidade de São Paulo, \\ São Paulo-SP, Brasil
}

\begin{abstract}
Resumo
Para avaliar a influência de dietas deficientes em energia sobre o perfil hormonal, metabólico e clínico em bovinos, foram usados 12 garrotes aleatoriamente distribuídos em três grupos com quatro animais para receber por 140 dias, as rações: (G1) adequada, para ganho de peso de 900g/dia (17,7 Mcal/d de ED e 13\% de PB); (G2) 80\% dos requerimentos de mantença (5,8 Mcal/d de ED e 7\% de PB); e (G3) 60\% dessas exigências (4,7 Mcal/d de ED e 5\% de PB). Nos grupos G2 e G3 houve acentuada diminuição do peso vivo e do consumo de alimentos. O déficit energético provocou redução destacada nos teores sanguíneos de IGF-1 e $\mathrm{T}_{3}$. A perda de peso foi uma direta consequência do menor consumo de alimentos, da qualidade inferior de ração ingerida e da menor atuação de IGF-1 e T . A mensuração da altura dos animais ao término do experimento apresentou uma diferença no G1 de 59\% e 73\% maior que G2 e G3, respectivamente. O IGF-1 foi considerado o principal indicador do status energético, pois diminuiu de maneira sensível e rápida sua concentração no decorrer do tempo experimental; este hormônio foi diretamente influenciado pelos teores de $\mathrm{T}_{3}$.
\end{abstract}

Palavras-chave: Bovinos. IGF-1 . $\mathrm{T}_{3}$. Desempenho. Ruminantes.

\begin{abstract}
To evaluate the influence of diets with different degrees of energy deficiency on the hormonal profile, and on metabolic and clinical states of steers, 12 steers were randomly distributed in three groups of four animals each. The groups received the following diets for 140 days: (G1) 100\% of the maintenance to stimulate to weight gain of 900 gr/day (DE: 17.7 Mcal/d and 13\% de CP); (G2) 80\% of the maintenance (DE: $5.8 \mathrm{Mcal} / \mathrm{d}$ and 7\% de CP); (G3) 60\% of the same requirements (DE: $4.7 \mathrm{Mcal} / \mathrm{d}$ and 5\% de $\mathrm{CP}$ ). In both energy deficiency groups (G2 and G3) there was a decrease in body weight and in feed intake during experimental period. In relation to hormonal profile, the energy deficit caused an acute reduction in plasma levels of IGF-1 and $\mathrm{T}_{3}$. Weight loss was due to lower feed intake, poor quality of diet ingested and also due to low concentrations of IGF-1 and $\mathrm{T}_{3}$. Measuring height of animals at the end of the experiment showed a difference of 59\% in G1 and 73\% higher than G2 and G3, respectively. IGF-1 was considered the best indicator of the energetic status, because its blood levels reduction was sensible and rapid during the dietary energy deficit; and it was influenced directly by level of $\mathrm{T}_{3}$.
\end{abstract}

Keywords: Bovine. IGF-1 . T 3 . Performance. Ruminants.

\section{Introdução}

A maioria dos bovinos brasileiros (94\%) é criada em condições extensivas de manejo, alimentando-se basicamente de capins tropicais, em especial do gênero Braquiária, suplementados ou não com sal mineralizado ou sal proteinado ${ }^{1}$. Cerca de $75 \%$ do crescimento dos capins tropicais ocorre no período chuvoso, quando as concentrações de energia, proteína e fósforo estão altos. Sem suplementação adequada no período seco, ocorre o surgimento de deficiências nestes nutrientes que quase invariavelmente provocam queda de produtividade e prejuízos econômicos ${ }^{2,3}$.

Essas deficiências podem desencadear várias alterações metabólicas, em especial no perfil hormonal dos animais. Nessas situações de deficiência, as necessida-

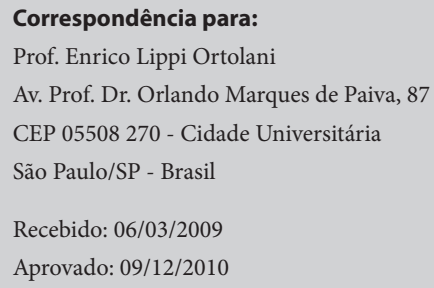


des energéticas e proteicas para o organismo são supridas a partir da mobilização de nutrientes dos tecidos, o que resulta na perda de condição corporal e de peso ponderal ${ }^{4,5}$. Geralmente, esta perda de peso vivo é gradual e passa a ser mais destacada quanto maior for o grau da deficiência nutritiva ${ }^{6,7}$.

Dentre os hormônios que regulam o crescimento e a utilização dos nutrientes, em especial da energia, o IGF-1 (Insulin Like Growth Factor 1) tem papel destacado pois está envolvido com o desenvolvimento e diferenciação dos tecidos, especialmente no aumento da síntese de proteínas.

Os hormônios tireoideos desempenham papel chave no metabolismo basal e, dentre os efeitos gerais destes hormônios no organismo, podemos $\operatorname{citar}^{8} \mathrm{a}$ estimulação da síntese de proteínas, o aumento dos processos de glicólise, gliconeogênese e absorção intestinal de glicose, a estimulação da atividade cárdiocirculatória por meio de batimentos cardíacos, débito cardíaco e fluxo sanguíneo e desenvolvimento neuronal e o aumento da transmissão em células neurais. Embora o hormônio Tiroxina $\left(\mathrm{T}_{4}\right)$ seja secretado em maior quantidade pela glândula tireoide, o Triiodotironina $\left(\mathrm{T}_{3}\right)$ é a forma biologicamente ativa no organismo 9 , e, portanto deve ser aferido nos estudos de metabolismo energético, principalmente nos casos de restrição alimentar.

Os ruminantes têm a capacidade de se adaptarem a certos períodos de subnutrição, pois reduzem as necessidades de mantença por meio da diminuição da taxa de metabolismo basal, efeito este mediado pela menor concentração dos hormônios tireoidianos ${ }^{6,7,10}$. Entretanto faltam estudos que avaliem estas características em casos de deficiência energética mais prolongada em bovinos em crescimento.

O presente trabalho foi conduzido para avaliar a influência por longo período do oferecimento de dietas deficientes em energia sobre o desempenho animal correlacionando o perfil hormonal e clínico nos bovinos em crescimento.

\section{Material e Método}

Foram utilizados 12 bovinos mestiços, machos, hígidos, com idade aproximada de 10 meses e peso médio de $165 \mathrm{~kg}$ no início do experimento. Os animais foram mantidos em baias individuais, onde havia a possibilidade de avaliar o consumo alimentar.

O período experimental foi de 140 dias (divididos em 10 períodos de 14 dias). Os 12 garrotes foram distribuídos aleatoriamente em três grupos experimentais, onde as dietas diferiam na proporção dos nutrientes, e foram formuladas de acordo com as tabelas nutricionais descritas no $\mathrm{NRC}^{11}$ para gado de corte. Os animais do Grupo 1, receberam dieta rica em proteína e energia, suficiente para ganho de $900 \mathrm{~g} /$ dia - 17,7 Mcal/dia de energia digestível (ED) e 13\% de proteína bruta (PB); do Grupo 2: receberam dieta com quantidade de proteína suficiente para ganho de 100 g/dia e energia com $20 \%$ a menos da exigência para mantença - 5,8 Mcal/dia de energia digestível (ED) e 7\% de proteína bruta (PB); e os do Grupo 3 receberam dieta com quantidade de proteína suficiente para a mantença dos animais e energia com $40 \%$ a menos da exigência para mantença - 4,7 Mcal/dia de energia digestível (ED) e $5 \%$ de proteína bruta (PB).

A ração dos três grupos de animais foi composta por bagaço de cana-de-açúcar cru, desidratado, feno de coast-cross (Cynodon dactylon) e concentrado comercial com 22\% de proteína bruta (PB) (Tabela 1).

As rações foram formuladas utilizando-se diferentes quantidades dos alimentos supracitados (Tabela 2). A quantidade de matéria seca (MS) de alimento oferecido equivalia a 2,75\% do peso vivo (PV) de cada garrote. Os animais foram pesados a cada 14 dias, com jejum mínimo de 12 horas, por dois dias consecutivos para o acompanhamento do ganho de peso. Para a elaboração da relação entre as variáveis foram utilizados os valores obtidos nas pesagens divididos pelo tempo em deficiência, e intitulados de - Peso Vivo Corrigido. 
Tabela 1 - Composição bromatológica* do feno de coast-cross, do concentrado e do bagaço de cana-de-açúcar utilizados durante o período experimental - São Paulo - 2004

\begin{tabular}{lccc}
\hline & Feno & Concentrado & Bagaço de cana \\
\hline \%MS (matéria seca) & 87,17 & 84,27 & 63,57 \\
\% PB (proteína bruta) & 7,05 & 17,63 & 1,42 \\
\% EE (extrato etéreo) & 1,75 & 5,11 & 1,27 \\
\% MM (matéria mineral) & 6,38 & 9,45 & 3,08 \\
\% NDT (total de nutrientes digestíveis) & 54,33 & 74,88 & 49,75 \\
\% FDN (fibra insolúvel em detergente neutro) & 76,20 & 27,01 & 90,02 \\
\%FDA (fibra insolúvel em detergente ácido) & 38,13 & 12,42 & 62,86 \\
\hline
\end{tabular}

* Determinações realizadas no laboratório de Doenças Nutricionais (FMVZ-USP)

** Calculado por meio da diferença da MS, PB, MM, EE e FB

Tabela 2 - Composição das dietas (matéria seca) oferecidas com os respectivos percentuais médios e desvios padrão dos alimentos utilizados durante o período experimental - São Paulo - 2004

\begin{tabular}{lccc}
\hline & GRUPO 1 (\%) & GRUPO 2 (\%) & GRUPO 3 (\%) \\
\hline CONCENTRADO & $59 \pm 12$ & $31 \pm 16$ & $21 \pm 12$ \\
FENO & $27 \pm 9$ & $5 \pm 7$ & $3 \pm 4$ \\
BAGAÇO DE CANA & $14 \pm 8$ & $64 \pm 12$ & $76 \pm 10$ \\
\hline
\end{tabular}

A mensuração da altura foi realizada a cada 14 dias, tomando-se as medidas do chão até a região das cernelhas dos animais, durante todo o período experimental.

A alimentação foi fornecida uma vez ao dia, às $8 \mathrm{~h}$ da manhã. Diariamente as sobras eram retiradas do comedouro. Durante os três últimos dias de cada período, as sobras foram pesadas e armazenadas à $20^{\circ} \mathrm{C}$, para posterior determinação de matéria seca, sendo estes subtraídos da quantidade de matéria seca (MS) oferecida para se determinar o consumo de matéria seca médio no período. Água e sal mineralizado foram oferecidos ad libitum durante todo o período experimental.

A cada 14 dias as amostras de sangue foram coletadas sempre na terceira hora após a alimentação dos garrotes. As concentrações de IGF-1 no plasma dos bovinos foram quantificadas por ensaio imunorradiométrico (IRMA) pós-extração utilizando-se o kit DSL-5600 (Diagnostic Systems Laboratories, Inc). A concentra- ção plasmática de $T_{3}$ foi determinada através do kit DPC/USA TKT 35 (Kit Coat-A-Count $\mathrm{T}_{3}$ total).

Todas as variáveis foram submetidas ao teste de KOLGOMOROV \& SMIRNOV para verificar se os dados apresentavam distribuição paramétrica. Quando a distribuição dos dados foi não paramétrica, estes foram transformados em $\log (\mathrm{x}+1)$. Todas as variáveis foram analisadas inicialmente por Teste $\mathrm{F}$ (ANOVA). As médias foram comparadas entre si pelo teste de Tukey a 5\% de significância. Para o estudo de relação entre duas variáveis, foram utilizados tanto a análise de regressão linear como o coeficiente de correlação. A significância obtida na regressão linear foi avaliada por meio do Teste $\mathrm{F}^{12,13}$.

\section{Resultados e Discussão}

A restrição energética alimentar prolongada trouxe alterações tanto na atividade metabólica (concentrações plasmáticas de $\mathrm{T}_{3}$ ), como nas concentrações de IGF-1 (Figura 1). 


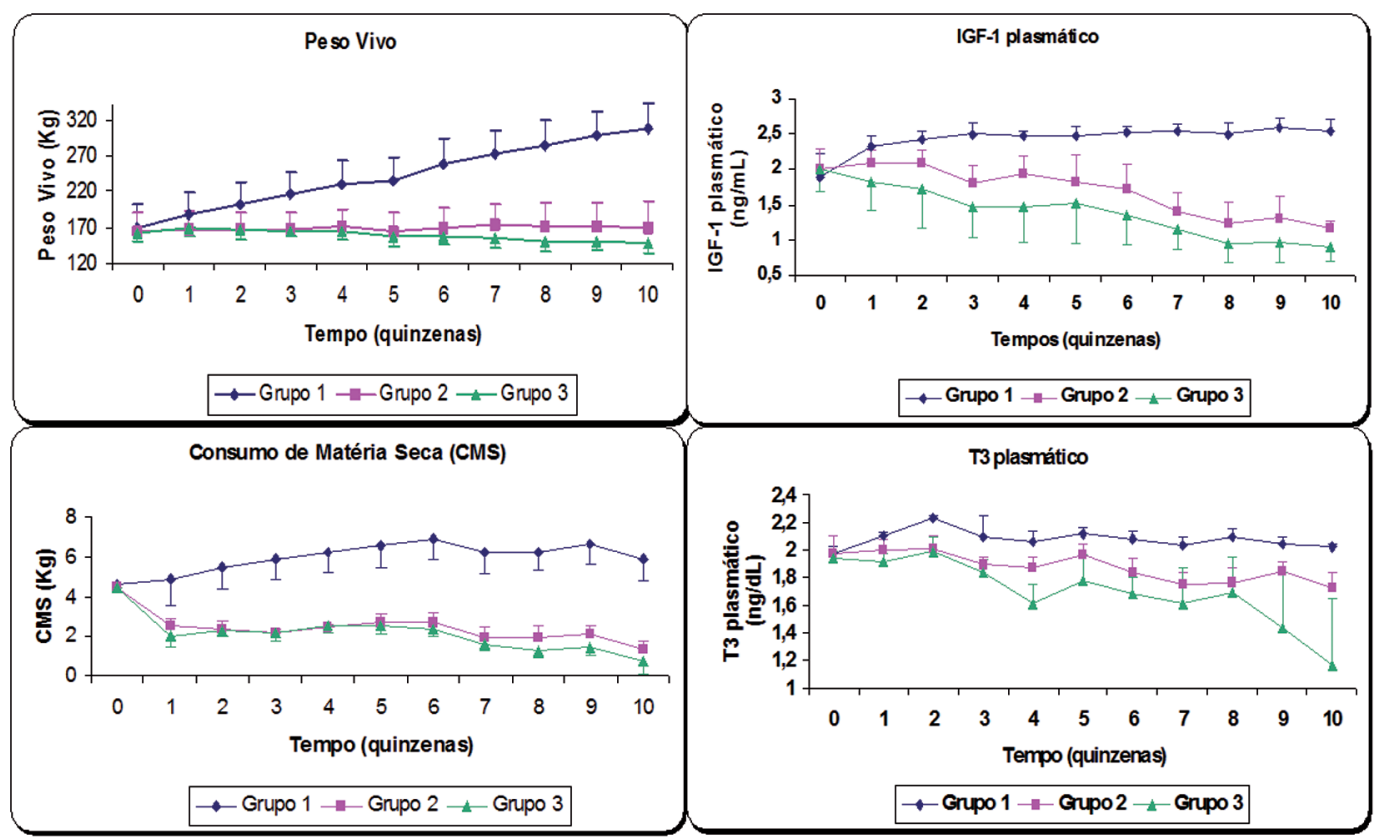

Figura 1 - Valores médios e desvios padrão do Peso Vivo (kg), Consumo de Matéria Seca (kg), concentração plasmática de IGF-1 $(\mathrm{ng} / \mathrm{mL})$ transformados em $\log (\mathrm{x}+1)$ e concentração plasmática de $\mathrm{T}_{3}(\mathrm{ng} / \mathrm{dL})$ transformados em $\log (\mathrm{x}+1)$ de bovinos do grupo 1 , que receberam dieta com altos teores de energia; grupo 2, que receberam teores moderados de energia; e grupo 3 que receberam baixos teores de energia no decorrer do período experimental - São Paulo - 2004

Os animais pertencentes aos grupos submetidos à restrição energética manifestaram destacada redução na taxa de crescimento corporal, evidenciada pela manutenção do peso vivo, decorrente do baixo consumo de MS e de EB enquanto que os do grupo controle ganharam peso (Figura 1). O efeito de baixo consumo alimentar deve ser somado à menor ingestão global de energia, que proporcionou déficit nutricional importante, interferindo diretamente no metabolismo basal dos animais submetidos à subnutrição.

A matéria seca ingerida decresceu $(\mathrm{P}<0,002)$ nos grupos subalimentados, atingindo $47 \%$ e $61 \%$ nos grupos 2 e 3, enquanto que no controle existiu aumento da ordem de $21 \%$ (Figura 1).

O menor consumo de alimento nos bovinos deficientes ocorreu provavelmente pela maior quantidade de fibra insolúvel detergente neutro (FDN). Segundo Forbes $^{14}$, o FDN é um dos componentes da dieta que regula o consumo de alimentos devido ao maior enchimento ruminal.
De maneira geral, em dietas com alta densidade energética e baixo teor de fibras os ruminantes regulam o consumo para atender a exigência energética, porém dietas com alto teor de fibra e baixa densidade energética, como o que ocorreu nas dietas dos grupos 2 e 3 , o consumo de matéria seca é limitado pelo efeito do enchimento do trato gastrintestinal ${ }^{15,16}$.

Numa avaliação feita com estes animais, no $135^{\circ} \mathrm{d}$ deste experimento, e apresentada por Sucupira ${ }^{5}$ foi verificado que a taxa de passagem de líquidos do rúmen $(\% / h)$ foi cerca de 2,0 e 2,8 vezes menor no grupo 2 e 3 , respectivamente, que no grupo 1 , comprovando que o tempo de permanência do alimento foi superior em animais submetidos à subnutrição energética.

O teor de IGF-1 foi o melhor indicador do status energético, pois apresentou diferença entre os grupos alimentados com rações deficientes em relação ao controle (Figura 1) e também mostrou ser uma variável sensível devido ao baixo coeficiente de variação. Este é o principal hormônio do grupo conhe- 
cido como somatomedinas, os quais são produzidos no fígado, estimulado pelo hormônio de crescimento (HC). Vários órgãos têm receptores para IGF-1, mas se destacam a epífise óssea cartilagínea, a glândula mamária e a musculatura esquelética. Nos ossos o IGF-1 estimula o crescimento longitudinal do esqueleto. A mensuração da altura no início do estudo não apresentou diferença entre os grupos (1- $110 \pm 5$; 2$108 \pm 3$; 3- $110 \pm 3 \mathrm{~cm}$ ), contudo ao término do expe- rimento, 140 dias após, a diferença de crescimento em altura no grupo controle $(120 \pm 5 \mathrm{~cm})$ foi $59 \%$ e $73 \%$ maior que nos grupos 2 e 3 , respectivamente.

$\mathrm{Na}$ musculatura o IGF-1 tem um efeito principalmente hipertrófico e em menor grau hiperplásico, influenciando a captação de aminoácidos e a síntese proteica pelas células da musculatura estriada ${ }^{17,18}$. A correlação entre IGF-1 e o peso vivo corrigido foi alta $(\mathrm{r}=0,857)$ (Figura 2). O peso vivo ficou diretamente

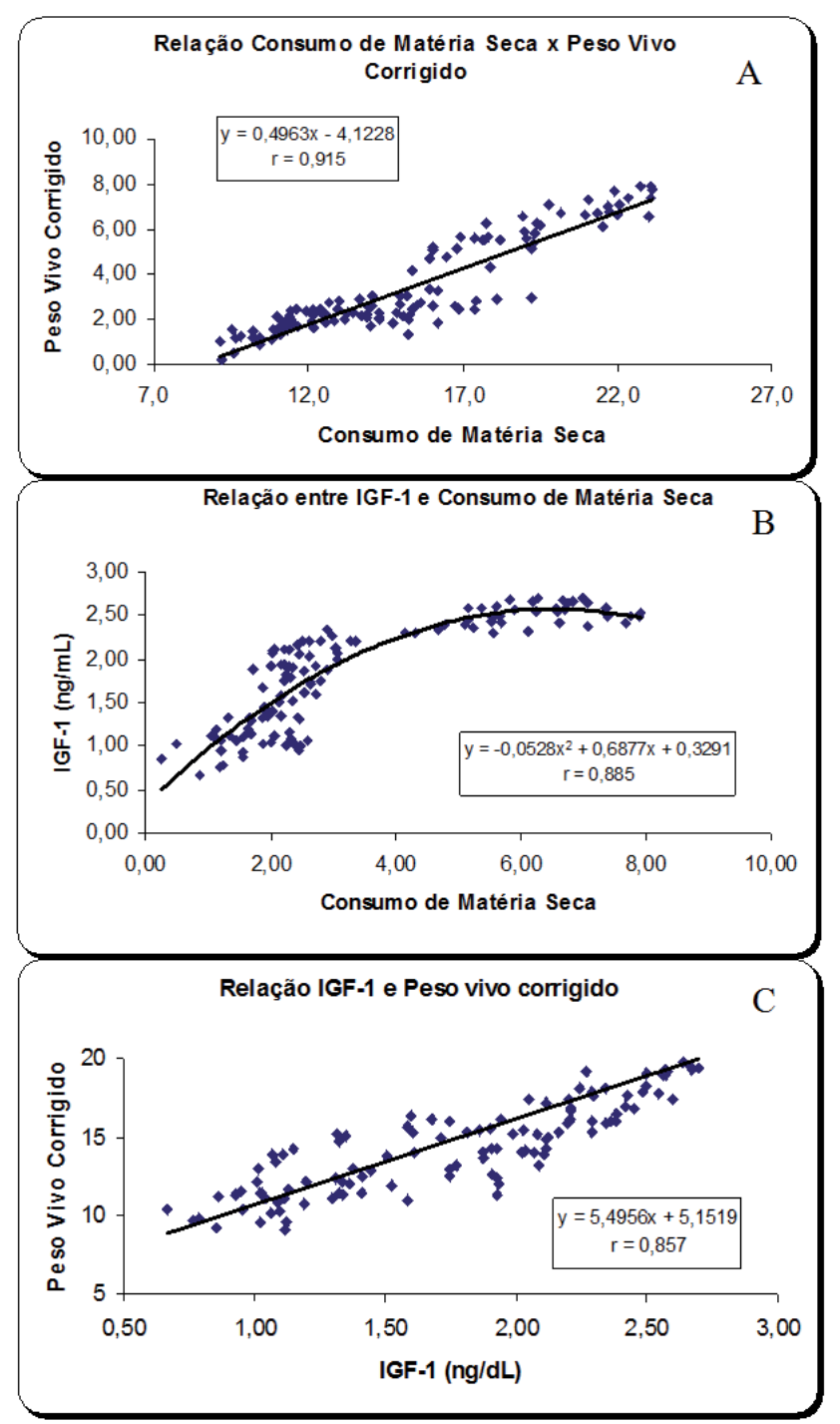

Figura 2 - Relação entre: A - Consumo de Matéria Seca (kg) e Peso Vivo (kg), B concentração IGF-1 (ng/mL) transformado em $\log (\mathrm{x}+1)$ e C - Consumo de Matéria Seca $(\mathrm{kg})$ e concentração IGF-1 (ng/mL) transformado em $\log (\mathrm{x}+1)$ e Peso Vivo $(\mathrm{kg})$, de bovinos do grupo 1, que receberam dieta com altos teores de energia; grupo 2, que receberam teores moderados de energia; e grupo 3, que receberam baixos teores de energia no decorrer do período experimental - São Paulo - 2004 
correlacionado com o maior consumo total de alimentos $(\mathrm{r}=0,915)$, o qual também se correlacionou com os teores de IGF-1 $(r=0,885)$ (Figura 2).

Além destes fatores a concentração de IGF-1 esteve positivamente correlacionada com $\mathrm{T}_{3}(\mathrm{r}=0,833)$ (Figura 3). Este último parece diminuir a expressão do RNA mensageiro do IGF-1 modulado e controlado pelo $\mathrm{HC}^{17}$, Isto parece ocorrer principalmente nos casos hipertireoidismo em que o excesso de $\mathrm{T}_{3}$ provoca menor produção de IGF-1, promovendo redução na síntese proteica muscular ${ }^{19}$. Em condições naturais de normotiroidismo, bezerros sem restrição nutricional apresentaram relação positiva significativa entre o $\mathrm{T}_{3}$ e o IGF- $1^{20}$.

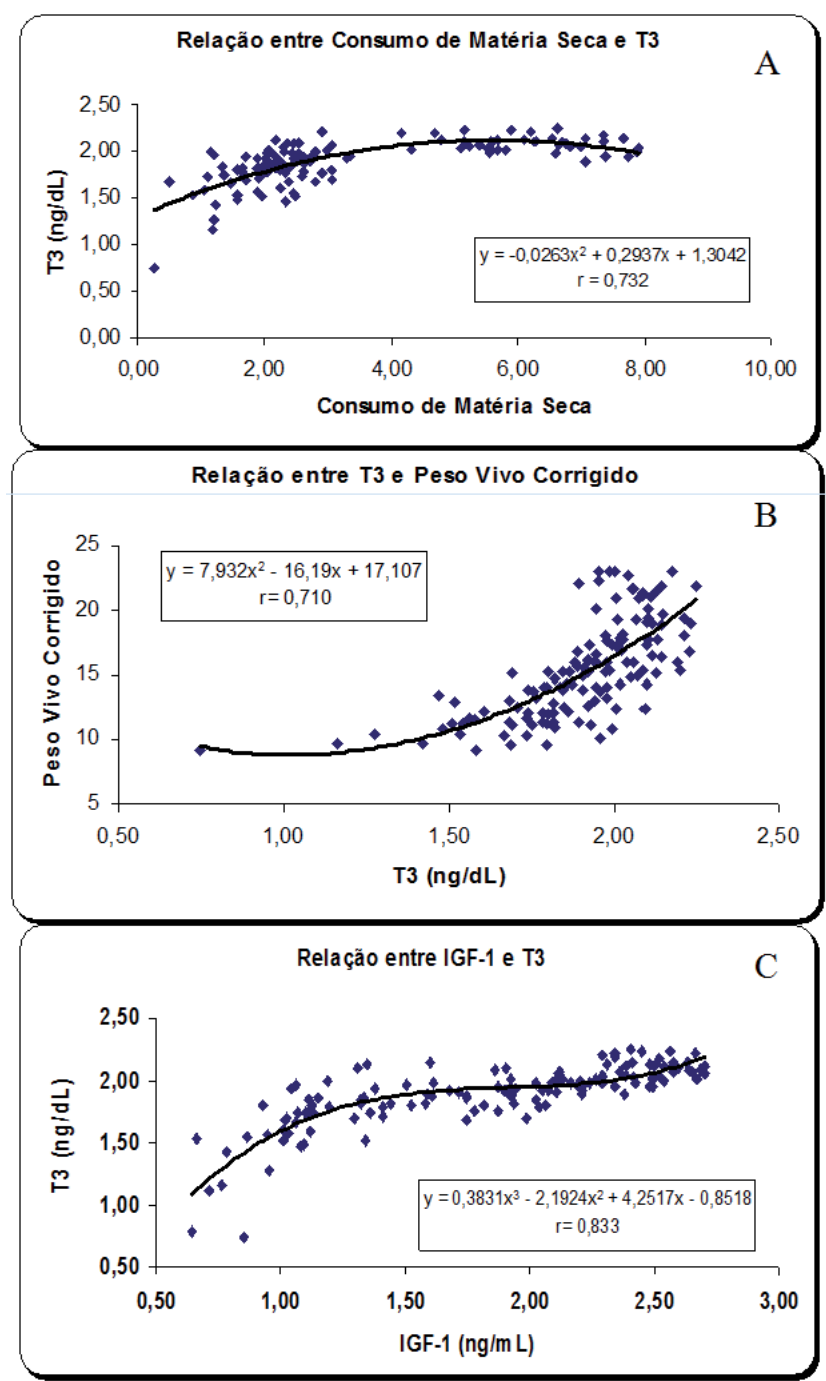

Figura 3 - Relação entre: A -concentração Consumo de Matéria Seca $(\mathrm{kg})$ e $\mathrm{T}_{3}(\mathrm{ng} / \mathrm{dL})$ transformado em log $(\mathrm{x}+1) ; \mathrm{B}$ - concentração $\mathrm{T}_{3}(\mathrm{ng} / \mathrm{dL})$ transformado em $\log (\mathrm{x}+1)$ e Peso Vivo $(\mathrm{kg})$ e C -concentração IGF-1 (ng/mL) transformado em $\log (\mathrm{x}+1)$ e $\mathrm{T}_{3}$ $(\mathrm{ng} / \mathrm{dL})$ transformado em $\log (\mathrm{x}+1)$, de bovinos do grupo 1, que receberam dieta com altos teores de energia; grupo 2, que receberam teores moderados de energia; e grupo 3, que receberam baixos teores de energia no decorrer do período experimental São Paulo - 2004 
A restrição energética influenciou diretamente $\mathrm{o} \mathrm{T}_{3}$, pois existiu diferença entre o grupo controle e os dois submetidos à subnutrição já no $6^{\circ}$ período de experimentação (Figura 1). Isto indica que existiu menor biotransformação de $\mathrm{T}_{4}$ para $\mathrm{T}_{3}$, mediada usualmente pelas enzimas 5 'deiodinases tipo I e II, que tem sua ação controlada positivamente pela quantidade de energia disponível nos órgãos, refletindo portanto, o estado nutricional dos animais ${ }^{21}$.

Parte menor da síntese de $\mathrm{T}_{3}$ é proveniente da conjugação de aminoácidos tirosínicos, ou seja, uma molécula de tirosina que contém um átomo de iodo (monoiodotirosina - MIT) se associa a uma idêntica molécula de tirosina que alberga dois iodos no composto (diiodotirosina- DIT). Assim a soma de um MIT mais um DIT forma a triiodotironina, também chamada de $\mathrm{T}_{3}$. O MIT e o DIT são oriundos de um complexo glicoproteico denominado tireoglobulina, fundamental para a síntese dos hormônios tireoideanos. Tanto a insulina como o IGF-1 são necessários para a síntese da tireoglobulina. Em casos de subnutrição energética ocorre diminuição na síntese de tireoglobulina por menor atuação da insulina e do IGF-1, também influenciados pela dieta ${ }^{9}$. De fato, existiu alta correlação positiva entre $\mathrm{T}_{3}$ e IGF-1 $(\mathrm{r}=0,833)$ (Figura 3 ).

Classicamente, é descrita uma relação íntima entre os hormônios tireoideanos e o crescimento nos animais, que são acompanhados de aumento no metabolismo geral ${ }^{18}$. Isto explica a correlação positiva entre $\mathrm{o}_{3}$ e o peso vivo corrigido $(\mathrm{r}=0,710)$ (Figura 3 ) e

\section{Referências}

1.ANUALPEC 2006. Anuário da pecuária brasileira. São Paulo: FNP Consultoria e AgroInformativos, 2006. 369 p.

2.GONZÁlEZ, F. H. D. Uso do perfil metabólico para determinar o status nutricional em gado de corte. In: GONZÁlEZ, F. H. D.; BARCELLOS, J.; PATINO, H. O.; RIBEIRO, L. A. (Ed.). O. Perfil metabólico em ruminantes: seu uso em nutrição e doenças nutricionais. Porto Alegre: Gráfica da Universidade Federal do Rio Grande do Sul, 2000. p. 63-74.

3.PEDREIRA, J. V. S. Crescimento estacional dos capins colonião, gordura, jaraguá e pangola. Boletim da Indústria Animal, v. 30, p. 59-146, 1973. com o aumento de consumo de alimentos $(r=0,732)$ (Figura 3).

De modo geral, o elevado grau de carência energética fez com que os bovinos do grupo 3, apresentassem menores valores de IGF-1 e $\mathrm{T}_{3}$ que os do grupo 2 . Com isso, essas variáveis indicaram com sensibilidade e presteza os efeitos da deficiência que os animais foram submetidos.

\section{Conclusões}

Estes resultados permitem concluir que a deficiência de energia prolongada de bovinos em crescimento desencadeia alterações clínicas com acentuada diminuição do peso vivo e do consumo de alimentos, e hormonais com redução destacada nos teores sanguíneos de IGF-1 e $\mathrm{T}_{3}$.

A perda de peso foi consequência do menor consumo de alimentos, da qualidade inferior da ração ingerida e da menor atuação de IGF-1 e $\mathrm{T}_{3}$.

No atual estudo o IGF-1 foi considerado o principal indicador do status energético, pois diminuiu de maneira sensível e rápida sua concentração no decorrer da deficiência. A determinação da concentração deste hormônio pode ser uma importante ferramenta na detecção precoce desta deficiência.

\section{Agradecimentos}

A pesquisa foi realizada com o apoio financeiro da FAPESP e da VALLÉE S.A.

4.ENSMINGER, M. E. Feeding beef cattle. In: ENSMINGER, M. E. Cattle science. 6. ed. Danville, Illinois: The Interstate, 1987. cap. 8, p. 239-348.

5.SUCUPIRA, M. C. A. Estudo comparativo de exames clínico-laboratoriais no diagnóstico de carência energética prolongada em garrotes. 2003. $173 \mathrm{f}$. Tese (Doutorado em Clínica Médica) - Faculdade de Medicina Veterinária e Zootecnia, Universidade de São Paulo, São Paulo, 2003.

6.CHILLIARD, Y.; BOCQUIER, F; DOREALL, M. Digestive and metabolic adaptation of ruminants to undernutrition and consequences on reproduction. Reprodutive Nutrition Development, v. 38, n. 2, p. 131-152, 1998. 
7.OETZEL, G. R. Protein energy malnutrition in ruminants. The Veterinary Clinics of North America: food animal practice, v. 4, n. 2, p. 317-329, 1988.

8. CAPEN, C. C.; MARTIN, S. L. The thyroid gland. In: PINEDA, M. H.; DOOLEY, M. P. (Ed). McDonald's veterinary endocrinology and reproduction. Ames: Iowa State Press, 2003. 597 p.

9.BERNE, R. M.; LEVY, M. N. Fisiologia. Rio de Janeiro: Elsevier, 2004. 1082 p.

10.GÓMEZ-PASTÉN, M.; MORA, O.; PEDRAZA-CHAVERRI, J.; SHIMADA, A. The effect of a long term feed restrition on metabolism and tissue composition of goats. Journal of Agricultural Science, v. 132, p. 227-232, 1999.

11.NRC. NATIONAL RESEARCH COUNCIL. Committe on Animal Nutrition. Nutrient requeriments of beef cattle. 6 . ed. Washingyon: National Academy of Science, 1984.

12.LITTLE, T. M.; HILLS, F. J. Agricultural experimentation design and analysis, New York: John Wiley \& Sons, 1978. 350 p.

13.SAMPAIO, I. B. M. Estatística aplicada à experimentação animal. 2. ed. Belo Horizonte: Fundação de Ensino e Pesquisa em Medicina Veterinária e Zootecnia, 2002. p. 265.

14.FORBES, J. M. Voluntary food intake and diet selection in farm animals. New York: CAB International, UK, 1995. 532 p.

15. CARVALHO, S.; KIELING, R. Fibra na alimentação de ruminantes. Rio Grande do Sul: Curso de Engenharia de
Produção Agroindustrial - Feevale, RS. 2002. Disponível em: <http://www.feevale.br/triade/icet/096.doc >. Acesso em: nov. 2002.

16. VAN SOEST, P.J. Nutritional ecology of the ruminant. 2. ed. Ithaca: Comstock Publ., 1994. cap. 21, p. 337-353.

17.LAWRENCE, T. L. J.; FOWLER, V. R. Growth of farm animals. 2. ed. New York: CAB International, 1997. 330 p.

18. SQUIRES, E. J. Applied animal endocrinology. Massachusetts: CABI publishing USA, 2003. $234 \mathrm{p}$.

19. HYNES, M. A.; VAN WYK, J. J.; BROOKS, P. J.; D'ERCOLE, A. J.; JANSEN, M.; LUND, P. K. Growth hormone dependendence of somatomedin-C/insulin-like growth factor I and insulinlike growth factor II nRNA. Molecular Endocrinology, v. 1, p. 233-242, 1987.

20.ELSASSER, T. H.; RUMSEY, T. S.; KAHL, S. Relationship between the thyroid and somatotropic axes in steers II: effects of thyroid status on plasma concentrations of insulin-like growth factor I (IGF-1) and the IGF-1 response to growth hormone. Domestic Animal Endocrinology, v. 10, n. 2, p. 7185, 1993.

21.GERRITS, W. J. J.; DECUYPERE, E.; VERSTEGEN, M. W. A.; KARABINAS, V. Effect of protein-free energy intake on plasma concentrations of insulin-like growth factor I and thyroid hormones in preruminant calves. Journal Animal Science, v. 76, n. 5, p. 1356-1363, 1998. 